\title{
Determinação dos elementos-traço (Zn, Co e Ni) em sedimentos da Plataforma Continental Amazônica sob influência da descarga do rio Amazonas
}

\author{
Gilmar Wanzeller SIQUEIRA ${ }^{1}$, Simone de Fátima Pinheiro PEREIRA1, Fábio Marques APRILE² \\ RESUMO \\ Esta pesquisa foi desenvolvida na Plataforma Continental Amazônica (PCA) no trecho compreendido entre os cabos Orange (AP) \\ e Maguari (PA), para determinar os teores de $\mathrm{Zn}$, Co e Ni nos sedimentos superficiais, identificando o papel dos sedimentos como \\ fonte ou reserva de elementos-traço. A concentração dos elementos metálicos apresentou a seguinte associação: $\mathrm{Zn}>\mathrm{Ni}>\mathrm{Co}$. Os \\ sedimentos localizados na PCA podem ser considerados como sítio de ocorrência natural dos elementos metálicos, não havendo \\ influência de fontes poluidoras na liberação destes para o sistema.
}

PALAVRA CHAVE

Elementos-traço, sedimento, Plataforma Continental Amazônica

\section{Determination of trace elements ( $\mathrm{Zn}$, Co and $\mathrm{Ni}$ ) in sediments at the Amazon Continental shelf on influence of the Amazon River discharge}

\section{ABSTRACT}

Determination of trace elements $(Z n, C o$ and Ni) in sediments at the Amazon Continental Shelf on influence of the Amazon River discharge This research was developed at Amazon Continental Shelf(ACS) between the Orange Cape (Amapá State) and the Maguari Cape (Para' State), to determine the levels of zinc, cobalt and nickel in the superficial sediments identifying its inputs and outputs. The rate of these metallic elements in the sediments decreases following $Z n>N i>C o$. The concentrations of total metals in the surface sediments range from $Z n$ $=52.8-159.5 ; \mathrm{Ni}=21.7-47.4$ and $\mathrm{Co}=14.3-48.8\left(\mathrm{mg} \cdot \mathrm{kg}^{-1}\right)$. The levels of trace elements observed in the sediments at $A C S$ are of natural occurrence. Pollution sources of metallic elements were not observed.

\section{KEY WORDS}

trace elements, sediment, Amazon Continental Shelf

\footnotetext{
${ }^{1}$ Laboratório de Química Analítica e Ambiental, Departamento de Química, Centro de Ciências Exatas e Naturais da UFPA, Campus Universitário do Guamá. Av. Augusto Corrêa 1 , Belém-PA, 66075-100,E-mail: gilmar@ufpa.br; simonefp@ufpa.br

${ }^{2}$ Instituto Nacional de Pesquisa da Amazônia, Coordenação de Pesquisas em Biologia Aquática. Av. André Araújo 2936, Manaus- AM, 69060-001,Brasil. E-mail: aprilefm@hotmail.com Fone: (92) 36433391
} 


\section{INTRODUÇÃO}

O litoral brasileiro estende-se por $7.700 \mathrm{~km}$ de norte a sul entre $4^{\circ} \mathrm{N}$ a $32^{\circ} \mathrm{S}$, exibindo inúmeros ecossistemas. A diversidade desses sistemas é altamente dependente das condiçōes climáticas, morfológicas, e dos processos hidrogeoquímicos.

Segundo Förstner e Wittmann (1983) e Muniz et al. (1996), processos como intemperismo, erosão e transporte dos elementostraço no meio ambiente, têm sido alterados em larga escala pela atividade antrópica, podendo apresentar efeito de acumulação biológica (bioacumulação e biomagnificação). Para Tavares et al. (1992), a bioacumulação e biomagnificação podem ser responsáveis pelo aumento dos teores de elementos-traço a níveis altamente tóxicos para diferentes espécies da biota.

Os elementos-traço de origem natural, de modo geral, ocorrem como componentes traços de minerais detríticos, já os de origem antrópica, uma vez descarregados em águas superficiais, são transportados associados ao material em suspensão ou eventualmente sob a forma de colóides (Förstner e Wittmann, 1983; Salomons e Förstner, 1984).

Siqueira (2003) destaca a importância do estudo dos elementos metálicos na Plataforma Continental do Amazonas (P.C.A.), devido a presença desses elementos em associação a grande quantidade de material em suspensão transportado pelo rio Amazonas, e em menor grau pelo rio Pará, que em função das condiçōes físicas e físico-químicas, acabam permanecendo em suspensão e/ou são depositados como material de fundo no ambiente estuarino e marinho. Segundo Siqueira (2003), as condições presentes na Plataforma, permitem uma verificação da biodisponibidade e distribuiçáo de elementos-traço nos sedimentos superficiais, sem interferência de poluição típica de áreas costeiras industrializadas e urbanizadas com forte impacto antropogênico.

Os objetivos deste trabalho foram (i) determinar os teores de elementos-traço ( $\mathrm{Zn}$, Co e Ni) nas frações total e móvel nos sedimentos superficiais da Plataforma Continental Amazônica; (ii) identificar o papel dos sedimentos como fonte ou reserva de elementos-traço; (iii) conhecer o nível de background na área da Plataforma sob influência das descargas das bacias dos rios Amazonas e Pará; e (iv) estabelecer o percentual biodisponível dos elementos-traço à biota associada.

\section{MATERIAIS E MÉTODOS}

A área de pesquisa está inserida dentro da Zona Econômica Exclusiva Brasileira (ZEE), na Plataforma Continental

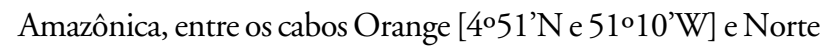
[1'30’ N e 50²9’W] noroeste da Margem Continental Norte Brasileira (Fig. 1).

O clima da região segundo a classificação de Köppen é do tipo tropical úmido, "Am" para a baía de Marajó (PA) e "Af" para o rio Pará, com elevadas temperaturas e altos índices pluviométricos

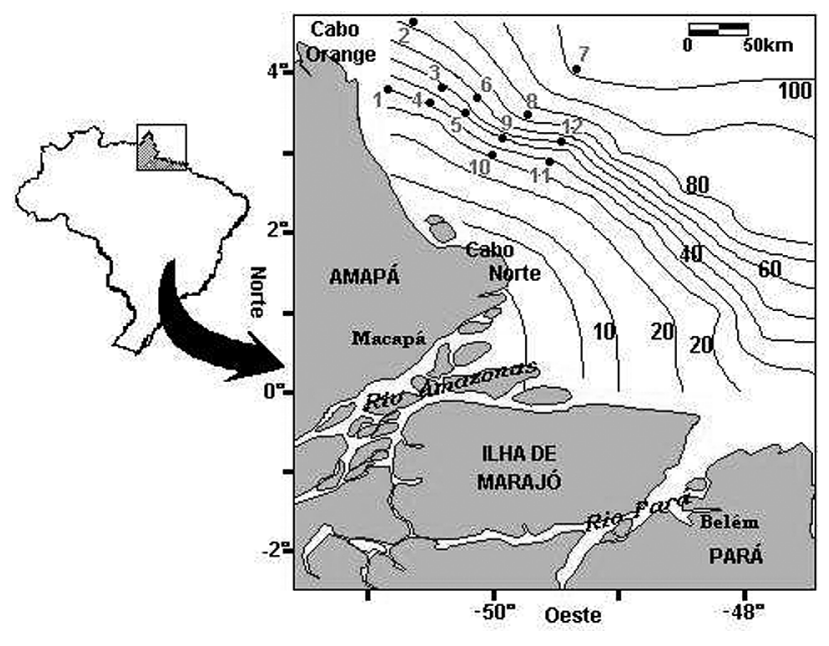

Figura 1 - Mapa da Plataforma Continental do Amazonas com a localização das estações de amostragem e suas respectivas isóbatas.

(Coutinho e Morais, 1970). Os ventos alísios são bastante atuantes sobre a plataforma durante todo o ano. A variação desses ventos está associada principalmente às oscilaçôes da Zona de Convergência Intertropical (ZCIT).

As águas do rio Amazonas ao desaguarem no oceano formam uma camada superficial de espessura variável entre 10 e $20 \mathrm{~m}$, sob a qual existe uma camada salgada, que migra em direção ao continente. Forma-se nesse ponto uma estratificação vertical de origem física (densidade), que se estende pela P.C.A. de 60 até $185 \mathrm{~km}$ de largura, durante a seca, e de 80 a $230 \mathrm{~km}$ durante as cheias (Gibbs, 1970 e Diégues, 1972).

O suprimento sedimentar fornecido pelo rio Amazonas à plataforma continental está avaliado em 11 a $13 \times 10^{8}$ t.ano ${ }^{-1}$, representando em materiais totais $10 \%$ dos sedimentos fluviais do planeta (Meade et al., 1985). Do total de sedimentos transportados pelo rio Amazonas, 97\% provém das drenagens originárias nos Andes, sendo 62\% pelo rio Solimões (Andes Peruanos) e 35\% pelo rio Madeira oriundos dos Andes bolivianos (Seyler e Boaventura, 2001).

Foram realizadas amostragens de sedimentos superficiais em 12 pontos localizados entre os Cabos Orange e Norte (figura 1). A amostragem foi realizada durante a Operação Oceanográfica Norte II (10/1997), a bordo do NOc. Antares da Marinha do Brasil, dentro do Programa "Avaliação do Potencial Sustentável de Recursos Vivos na Zona Econômica Exclusiva” (REVIZEE), durante a fase de descarga mínima do rio Amazonas.

Os sedimentos superficiais foram coletados com amostradores do tipo Van-Veen e acondicionados em sacos plásticos em câmara fria à $-20^{\circ} \mathrm{C}$. No Laboratório de Nutrientes, Macronutrientes e Traços no Oceano do Instituto Oceanográfico da USP, foram realizados procedimentos de secagem em estufa à $60^{\circ} \mathrm{C} \pm 5$ até 
ausência total de umidade, e desagregação, pulverização e homogeneização com almofariz e pilão. Para determinação dos elementos metálicos foram utilizadas fraçóes de sedimento menores que $0,063 \mathrm{~mm}$.

A composição granulométrica foi determinada pelo método clássico de peneiramento fracionado. Para as fraçōes de areia muito fina e silte-argilosas $(<0,063 \mathrm{~mm} \mathrm{f})$, utilizou-se o procedimento de peneiramento úmido descrito por Jackson (1965). O carbono orgânico (C-org) foi determinado pelo método de oxidação com dicromato de potássio em meio ácido a $" 80^{\circ} \mathrm{C}$. A concentração de matéria orgânica foi obtida a partir da multiplicação dos teores de C-org pelo fator 1,72 sugerido por Jackson (1965).

A fração móvel ou biodisponível dos elementos-traço foi obtida pelo método de extração ácida. Em um erlenmeyer pirex de $50 \mathrm{~mL}$ com tampa foi acrescentado $1 \mathrm{~g} \pm 0,001$ de sedimento fino e $20 \mathrm{~mL}$ de $\mathrm{HCl} 0,5 \mathrm{~N}$ sob agitação mecânica por 24 horas. Após o material foi centrifugado e filtrado em papel de filtro Whatman 44. Os extratos obtidos foram transferidos para balóes volumétricos de $25 \mathrm{~mL}$ e aferidos com solução de $\mathrm{HCl} 0,5 \mathrm{M}$, segundo procedimentos descritos por Agemiam e Chau (1976) e Chester (1978). A fração residual dos elementos metálicos foi obtida pelo método de extração ácida enérgica (Tessier et al., 1979, Salomons e Förstner, 1980). Em um erlenmeyer pirex de $50 \mathrm{~mL}$ foi acrescentado $1 \mathrm{~g} \pm 0,001$ de sedimento fino seco e uma solução contendo $5 \mathrm{~mL}$ de $\mathrm{HNO}_{3}+20 \mathrm{~mL}$ de $\mathrm{HF}+2 \mathrm{~mL}$ de $\mathrm{HClO}_{4}$ concentrados. Levou-se a solução à chapa de aquecimento até a secagem completa. Foi adicionado ao resíduo seco $10 \mathrm{~mL}$ de $\mathrm{HCl} 6 \mathrm{M}$ e aquecido até uma nova secagem. Finalmente, acrescentou-se mais $10 \mathrm{~mL}$ de $\mathrm{HCl} 6 \mathrm{M}$ e levou-se a fervura para dissolução do sais, e em seguida as amostras foram transferidas para um balão de $100 \mathrm{~mL}$ e o volume completado com água deionizada. Todas as análises foram realizadas em duplicata, e as leituras feitas em espectrofotometria de absorção atômica de chama no Laboratório de Tecnologia Mineral e Meio Ambiente da SUDAM em Belém. Foi aplicada análise de correlação linear entre os elementos metálicos e teores de matéria orgânica a fim de determinar o grau de associação entre os mesmos.

\section{RESULTADOS E DISCUSSÃO}

Os sedimentos foram dominados pelas frações silte + argila (lama), sendo classificados segundo a classe textural de Shepard (1954) como sedimentos silte-argilosos. Foram exceção os pontos de 10 a 12 onde predominou a fração areia de influência marinha, com percentuais variando de 92,7 a $74,9 \%$, respectivamente. $O$ maior percentual da fração silte-argilosa foi encontrado no ponto $8(84,6 \%$, tabela 1$)$. Não foi observado um padrão de distribuição dos sedimentos lamosos e arenosos em função da variação das isóbatas da plataforma oceânica (figura 1), sendo que as classes texturais foram distribuídas, primordialmente, em função da variação da energia cinética na área de influência fluviomarinha. A carga sedimentar proveniente do rio Amazonas, e em menor concentração do rio Pará, é predominantemente formada por partículas finas com alta concentração de elementos siltosos. Esse material chega à Plataforma Continental com alta energia cinética, e permanece em suspensão e transporte só vindo a sedimentar-se no trecho norte-noroeste, onde a influência fluviomarinha passa a ser menor. O valor médio de carbono orgânico nas amostras de sedimentos superficiais da Plataforma Amazônica foi de 0,8\% 0,3 com uma variação entre 0,1 e 1,5\%. Em princípio, a distribuição do carbono orgânico em relação a análise textural dos sedimentos mostra que as maiores concentrações deste elemento ocorreram associadas as fraçōes lamosas. Os conteúdos de matéria orgânica, por sua vez, oscilaram entre 0,2 a $2,5 \%$, com média de $1,3 \% \pm 0,5$.

Com base na aplicação da análise de regressão linear e no Teste t para a concentração de carbono orgânico em função da variação da profundidade (tabela 2), pode-se afirmar que não houve qualquer relação entre os referidos parâmetros. Além da variância $\left(\mathrm{R}^{2}\right)$ obtida na análise de regressão ser muito baixa $(0,3817)$, o teste aplicado refuta qualquer similaridade entre as médias ao nível de significância estabelecido. Essa conclusão é igualmente válida entre a profundidade e os teores de matéria orgânica, uma vez que esta última foi calculada a partir dos resultados do carbono orgânico.

Os baixos valores de carbono orgânico encontrados nos sedimentos podem ser explicados pelos altos níveis de material em suspensão de origem terrígena, contendo elementos argilosos e silte-argilosos oriundos das descargas dos rios Amazonas e Pará. Além de ocasionar a redução da transparência da água e reduzir, por conseguinte, a produção primária, o material terrígeno se associa aos compostos orgânicos impedindo sua deposição. A forma dissolvida do C-org influencia a dinâmica dos ecossistemas

Tabela 1 - Granulometria e teores de carbono e matéria orgânica nos sedimentos da Plataforma Continental do Amazonas entre os Cabos Orange e Norte em 10/1997.

\begin{tabular}{|c|c|c|c|c|c|c|c|}
\hline Estação & Prof. (m) & Areia (\%) & Silte (\%) & Argila (\%) & Lama (\%) & C-org (\%) & MO (\%) \\
\hline 1 & 13,2 & 0,0 & 75,7 & 27,3 & 100,0 & 0,8 & 1,4 \\
\hline 2 & 74,0 & 0,4 & 64,9 & 34,6 & 99,6 & 0,9 & 1,5 \\
\hline 3 & 43,2 & 2,7 & 64,9 & 32,3 & 97,3 & 0,8 & 1,4 \\
\hline 4 & 16,8 & 0,0 & 73,5 & 26,5 & 100,0 & 0,8 & 1,3 \\
\hline 5 & 40,0 & 0,0 & 63,3 & 36,7 & 100,0 & 0,9 & 1,6 \\
\hline 6 & 87,6 & 0,0 & 68,1 & 31,8 & 100,0 & 1,5 & 2,5 \\
\hline 7 & 84,4 & 0,1 & 77,3 & 22,6 & 99,9 & 0,8 & 1,4 \\
\hline 8 & 70,0 & 0,0 & 84,6 & 15,4 & 100,0 & 0,7 & 1,2 \\
\hline 9 & 26,0 & 2,6 & 79,4 & 17,5 & 97,3 & 0,8 & 1,3 \\
\hline 10 & 15,0 & 92,7 & 7,1 & 0,2 & 7,3 & 0,1 & 0,2 \\
\hline 11 & 18,0 & 78,5 & 16,9 & 4,5 & 21,5 & 0,3 & 0,5 \\
\hline 12 & 63,3 & 74,9 & 17,9 & 7,2 & 25,1 & 0,8 & 1,3 \\
\hline Média & - & - & - & - & - & 0,8 & 1,3 \\
\hline D. Padrão & - & - & - & - & - & 0,3 & 0,5 \\
\hline
\end{tabular}


Tabela 2 - Resultado da Análise de Regressão Linear e do Teste $t^{\star}$ para as variáveis profundidade e $\mathrm{C}$-org na Plataforma Continental durante o período de estudo.

\begin{tabular}{cccccccc}
\hline & $\mathbf{N}$ & $\mathbf{R}^{2}$ & $\overline{\mathbf{x}}$ & $\mathbf{D .}$ Padrão & G.L. & $\boldsymbol{t}$ calc. & $\boldsymbol{t}$ tabela \\
\hline $\begin{array}{c}\text { Variável 1 } \\
\text { (Prof) }\end{array}$ & 12 & 0,3817 & 45,96 & 28,57 & 22 & 5,48 & 2,07 \\
$\begin{array}{c}\text { Variável 2 } \\
\text { (C-org) }\end{array}$ & 12 & & 0,76 & 0,33 & $(\mathrm{n}-2)$ & & \\
\hline "para $\mathrm{P}=<0,0001 \mathrm{e} \alpha=5 \%$ & & & &
\end{tabular}

aquáticos, atuando como precipitador de nutrientes necessários à produção primária e como complexador de metais pesados.

Em sedimentos costeiros os teores de zinco total estão em torno de 4,39mg. $\mathrm{kg}^{-1}$. Já em sedimentos ricos em compostos orgânicos, este elemento pode chegar a concentrações de 137 mg.kg-1 (Calvert e Price, 1970, apud Ribeiro 1979). Durante esta pesquisa os teores de zinco determinados variaram entre 52,83 e $159,46 \mathrm{mg} \cdot \mathrm{kg}^{-1}$ com média de $127,74 \mathrm{mg} \cdot \mathrm{kg}^{-1} \pm 39,18$ (tabela 3). As concentrações de $\mathrm{Zn}$ apresentadas neste trabalho corroboram com os resultados obtidos por Pereira et al. (2000) de 20 a $200 \mathrm{mgkg}^{-1}$ e por Lima (2003) de 40 a $167 \mathrm{mgkg}^{-1}$ para sedimentos provenientes da P.C.A. Observou-se um acréscimo de Zn na direção mais interna da Plataforma (figura 2), por vezes associado as frações de sedimentos mais finos.

A fração móvel de $\mathrm{Zn}$ variou de 5,82 a $36,31 \mathrm{mg} \mathrm{kg}^{-1}$, com média de $27,30 \mathrm{mg} \mathrm{kg}^{-1} \pm 10,25$ (tabela 3 ). O percentual biodisponível de zinco oscilou entre 10,9 e 30,3\%. Esse intervalo ficou abaixo do limite de $40 \%$ que segundo Souza et al. (1986) apud Hatje (1996), indica uma mobilidade natural do zinco nos sedimentos superficiais. O zinco é encontrado na natureza como sulfeto, muitas vezes associado a outros elementos metálicos como $\mathrm{Pb}, \mathrm{Cd}$ e Cu. Para Forstner e Wittimann (1983), os compostos de $\mathrm{ZnS}$ e $\mathrm{ZnCO}_{3}$ são as formas predominantes do zinco.
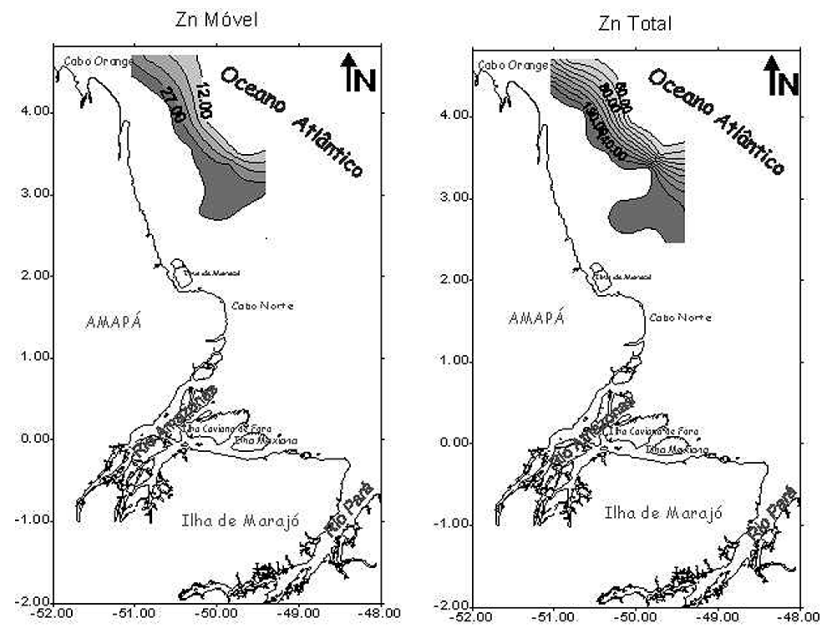

Figura 2 - Distribuição espacial dos isoteores de zinco nas frações móvel e total nos sedimentos superficiais da Plataforma Continental do Amazonas em 10/1997.
De acordo com Furlani et al. (1977), apenas uma fração do cobalto total, dependendo do material de origem, $\mathrm{pH}$ ou teor de argila, esta disponível para a biota. Na região estudada os teores totais de cobalto oscilaram entre 14,29 e 48,76 $\mathrm{mg} \mathrm{kg}^{-1}$ (média de $39,72 \mathrm{mg} \cdot \mathrm{kg}^{-1} \pm 11,90$, tabela 3). Pesquisas realizadas por Andrade e Patchineelam (2000) na P.C.A. registraram um teor médio de cobalto de $14,60 \mathrm{mg}^{-\mathrm{kg}^{-1}}$ nos sedimentos superficiais da Costa Amapaense, enquanto que Pereira et al. (2000) determinou, para a mesma região, uma concentração média de $20,93 \mathrm{mg} \cdot \mathrm{kg}^{-1}$. Pesquisa mais recente realizada por Lima (2003) demonstrou teores totais variando de 20 a $65 \mathrm{mg} . \mathrm{kg}^{-1} \mathrm{de}$ Co em sedimentos provenientes da foz do rio Amazonas.

A fração móvel de cobalto determinada ficou entre 4,60 e $7,02 \mathrm{mg} \cdot \mathrm{kg}^{-1}$ com média de 5,63mg. $\mathrm{kg}^{-1} \pm 0,79$ (tabela 3), e o percentual biodisponível entre 10,5 e 33,9\%. Este fato sugere uma baixa mobilidade de Co associado aos sedimentos superficiais nessa região. O predomínio da fração total de Co sobre a móvel, sugere que o transporte desse elemento-traço para o ambiente sedimentar ocorra de forma agregada a partículas cristalinas de minerais, acordando com estudos de Gibbs (1977), que afirma que as partículas cristalinas transportam $44 \%$ do cobalto total carreado pelo rio Amazonas. A distribuição dos teores de cobalto em relação a profundidade da Plataforma esta apresentada na figura 3 .

A fixação do níquel em sedimentos superficiais é determinada principalmente pela presença de óxidos/hidróxidos, carbonatos e silicatos de Fe e Mn (Forstner e Wittimann, 1983; Moore e Ramamoorthy, 1984). Durante esta pesquisa a fração total de níquel determinada oscilou entre 21,69 e 47,44 $\mathrm{mg} \mathrm{kg}^{-1}$, com

Tabela 3 - Concentrações das frações total e móvel dos elementos metálicos na Plataforma Continental Amazônica para o período de 10/1997.

\begin{tabular}{|c|c|c|c|c|c|c|c|}
\hline Estação & Prof.(m) & $\begin{array}{l}\text { Zn total } \\
\left(\mathrm{mg} \mathrm{kg}^{-1}\right)\end{array}$ & $\begin{array}{l}\text { Zn móvel } \\
\left(\mathrm{mg} \mathrm{kg}^{-1}\right)\end{array}$ & $\begin{array}{l}\text { Co total } \\
\left(\mathrm{mg}^{-k^{-1}}\right)\end{array}$ & $\begin{array}{l}\text { Co móvel } \\
\left(\mathrm{mg} . k g^{-1}\right)\end{array}$ & $\begin{array}{c}\text { Ni total } \\
\left(\mathrm{mg}^{-k^{-1}}\right)\end{array}$ & $\begin{array}{l}\text { Ni móvel } \\
\left({\left.\mathrm{mg} . \mathrm{kg}^{-1}\right)}^{-1}\right.\end{array}$ \\
\hline 1 & 13,2 & 148,38 & 35,74 & 44,68 & 6,97 & 44,63 & 9,87 \\
\hline 2 & 74,0 & 157,23 & 36,31 & 47,15 & 7,02 & 45,80 & 11,29 \\
\hline 3 & 43,2 & 152,69 & 35,94 & 48,76 & 6,51 & 47,04 & 10,49 \\
\hline 4 & 16,8 & 149,01 & 32,65 & 48,72 & 5,76 & 47,44 & 9,10 \\
\hline 5 & 40,0 & 159,46 & 28,50 & 43,13 & 4,89 & 45,32 & 7,98 \\
\hline 6 & 87,6 & 151,01 & 30,45 & 45,95 & 5,37 & 45,58 & 8,51 \\
\hline 7 & 84,4 & 144,45 & 31,65 & 46,04 & 5,46 & 46,16 & 9,03 \\
\hline 8 & 70,0 & 152,00 & 31,99 & 48,52 & 5,12 & 46,42 & 8,43 \\
\hline 9 & 26,0 & 136,39 & 32,22 & 44,71 & 6,01 & 44,18 & 9,37 \\
\hline 10 & 15,0 & 62,84 & 19,03 & 14,29 & 4,84 & 21,69 & 13,46 \\
\hline 11 & 18,0 & 52,83 & 5,82 & 24,98 & 4,60 & 23,48 & 11,47 \\
\hline 12 & 63,3 & 66,59 & 7,30 & 19,74 & 5,06 & 27,01 & 12,07 \\
\hline Média & - & 127,74 & 27,30 & 39,72 & 5,63 & 40,40 & 10,09 \\
\hline $\begin{array}{c}\text { D. } \\
\text { Padrão }\end{array}$ & - & 39,18 & 10,25 & 11,90 & 0,79 & 9,54 & 1,61 \\
\hline
\end{tabular}



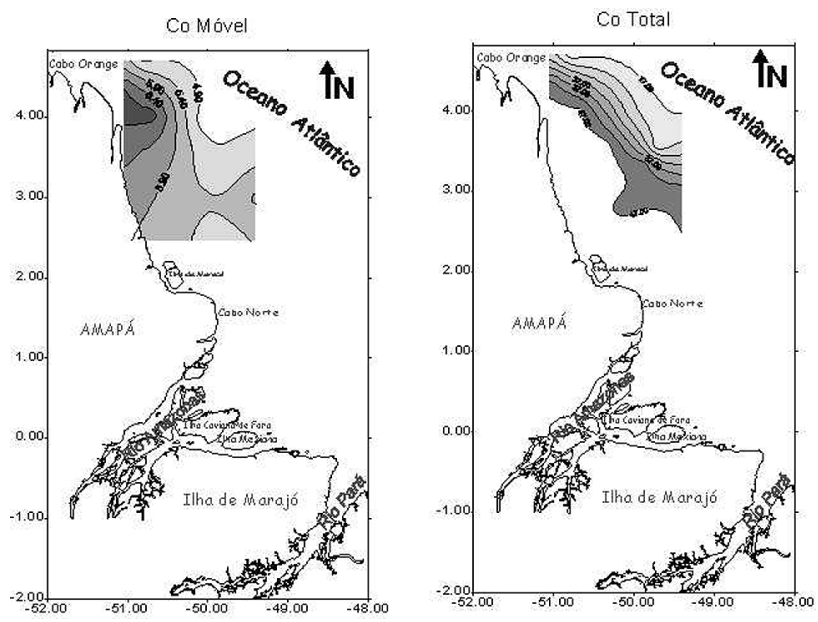

Figura 3 - Distribuição espacial dos isoteores de cobalto nas frações móvel e total nos sedimentos superficiais da Plataforma Continental do Amazonas em 10/1997.

média de 40,00 $\mathrm{mg} \mathrm{kg}^{-1} \pm 9,54$ (tabela 3). Estes dados são confirmados pelos trabalhos desenvolvidos por Andrade e Patchineelam (2000) e Lima (2003), que obtiveram concentraçōes de Ni nos sedimentos da Plataforma Amazônica na Costa Amapaense de $25,10 \mathrm{mg} \mathrm{kg}^{-1}$ e $57,31 \mathrm{mg} \mathrm{kg}^{-1}$, respectivamente. Os valores da fração móvel ficaram entre 7,98 e 13,46mg.kg ${ }^{-1}$, média de 10,09mg.kg ${ }^{-1} \pm 1,61$.

Em termos percentuais o níquel biodisponível foi o que apresentou a maior amplitude de variação dos elementos metálicos estudados, ficou entre 17,6 e $62,1 \%$. O níquel teve percentuais mais acentuados nas estaçōes com maiores isóbatas (figura 4), sugerindo uma associação deste elemento com outras frações geoquímicas do sedimento, como carbonato de cálcio.

Não foram constatados valores elevados de $\mathrm{Zn}$, Co e Ni, indicando o caráter natural do ecossistema. As fontes desses elementos-traço para a região provavelmente sejam o intemperismo e erosão das rochas das bacias de drenagem. As características oxidantes do sistema podem estar condicionando as formas químicas estáveis dos metais (íons, óxidos e hidróxidos). Além disso, nessas condições a presença de óxidos e hidróxidos complexados ou coloidais de $\mathrm{Fe}, \mathrm{Mn}$ e $\mathrm{Al}$ nas águas, segundo Förstner \&Wittmann (1983), funcionam como um importante suporte geoquímico para os elementos-traço.

Os elementos metálicos pesquisados são carreados pelo sistema hidrográfico Amazonas-Pará, conjuntamente com seus tributários, e precipitam como compostos insolúveis logo que entram no ambiente marinho. Em virtude das diferenças físico-químicas dos dois ecossistemas (fluvial e marinho), os metais são removidos da solução pelas reaçôes entre os íons e o material em suspensão. Este processo de remoção favorece a disponibilidade geoquímica, assim como um aumento do tempo de residência dos elementos na coluna de água, facilitando a sua migração para áreas mais

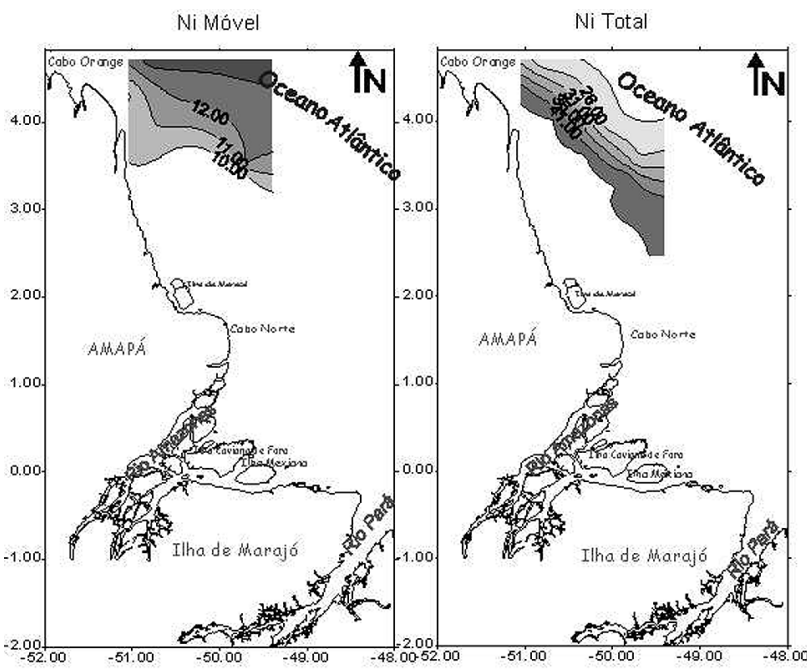

Figura 4 - Distribuição espacial dos isoteores de níquel nas frações móvel e total nos sedimentos superficiais da Plataforma Continental do Amazonas em 10/1997.

distantes da fonte. Já metais ligados preferencialmente a fração particulada são menos disponíveis geoquimicamente, e apresentam uma tendência a serem retirados da coluna de água por processos que favoreçam a sedimentação das partículas.

Outro fator que influencia a suspensão/sedimentação dos metais no sistema é o gradiente salino. Assim, em função da mistura das águas, tem-se uma remoção de elementos-traço da coluna de água através de processos de floculação, precipitação ou dissolução, cuja intensidade pode ser ampliada na zona de turbidez máxima. Segundo Salomons e Förstner (1984) com o aumento da salinidade a adsorção na fase particulada remanescente tende a diminuir em decorrência da competição com íon cloretos e ligantes orgânicos da água do mar.

A análise sedimentológica mostrou haver uma relação direta entre os elementos metálicos analisados e as suas respectivas retenções no compartimento sedimentar, visto que a composição argilosa, presente na maioria das amostras, tende a adsorver os elementos-traço como íons positivos (argilas apresentam carga elétrica negativa), enquanto na composição arenosa, os elementos tendem a lixiviação através de percolação de fluidos ou de outros fatores produzidos pelo intemperismo/erosão atuante no continente.

\section{CONCLUSÕES}

O gradiente decrescente dos elementos metálicos nas suas fraçóes total e móvel ficou assim estabelecido: $\mathrm{Zn}>\mathrm{Ni}>\mathrm{Co}$. Ocorreu uma dominância da fração residual com relação à fração móvel (diferença entre a fração total e móvel), justificado pelos baixos percentuais biodisponíveis encontrados. Este fato demonstra que na região os elementos-traço estudados estão 
agregados às partículas cristalinas, sendo controlado pelos tipos de rocha preexistentes que são intemperizadas no continente.

De maneira geral, constatou-se que os sedimentos superficiais localizados na Plataforma Continental do Amazonas podem ser considerados como sítio de ocorrência natural dos elementos metálicos, não havendo influência de fontes poluidoras na liberação destes para o sistema.

Existe uma associação entre a matéria orgânica com o níquel, cobalto e zinco, indicando que uma vez depositados esses elementos-traço podem ser influenciados, em parte, por moléculas orgânicas existentes nesse sistema.

\section{AGRADECIMENTOS}

Agradece-se a CAPES/PICDT/UFPA pela concessão de bolsa de estudo ao primeiro autor; ao Programa de Avaliação do Potencial Sustentável dos Recursos Vivos na Zona Econômica Exclusiva (REVIZEE/SCORE-NO) e, ao Programa de Pós Graduação em Oceanografia da USP, sinceros agradecimentos a Química Ieda Sofiatti responsável pelo Laboratório de Tecnologia Mineral e Meio Ambiente da Superintendência do Desenvolvimento da Amazônia (SUDAM) em Belém-PA pela colaboração nas análises.

\section{REFERÊNCIAS BIBLIOGRÁFICAS}

Agemiam, H.; Chau, A.S.Y. 1976. Evaluation of extraction techniques for the determination of metals in aquatic sediments. The Analyst, 101: 761-767.

Andrade, R.C.B.; Patchineelam, S.R. 2000. Especiação de metaistraço em sedimentos de florestas de manguezais com Avicennia e Rhizophora. Rev. Quimica Nova, 23(6): 733-736.

Chester, R. 1978. The partitioning of trace elements in sediments. Comitata Nazionale Energia Nucleare, 28p.

Coutinho, P.N.; Morais, J.O. 1970. Distribucion de los sedimentos en la Plataforma Continental Norte Y Nordeste del Brasil. Arq. Ciên. Mar., 10(1): 79-90.

Diégues, F.M.F. 1972. Introdução a oceanografia do Estuário Amazônico. Anais Hidrográficos. Tomo XXIX, p:129-157.

Förstner, U.; Wittmann, G.T.W. 1983. Metal Pollution in the Aquatic Environment. Berlin, Springer-Verlag, 486p.

Furlani, P.R.; Bataglia, O.C.; Valadares, J.M.A.S. 1977. Cobalto em solos do estado de São Paulo, Revista Brasileira de Ciência do Solo, 1: 65-67.

Gibbs, R.J. 1970. Circulation in the Amazon river estuary and adjacent Atlantic ocean. Jour. Mar. Res., New Haven, 28: 113123.

Gibbs, R.J. 1977. Transport phase of transition metals in the Amazon and Yukon rivers. Bull. Geol. Soc. Am., 88: 829-843.

Hatje, V. 1996. Contaminação por metais pesados no rio dos Sinos RS: Uma abordagem dinâmica a partir de balanços de massa. Dissertação de Mestrado, Universidade Federal Fluminense, Rio de Janeiro, 110 p.
Jackson, M. L. 1962. Soil chemical analysis. Englewood Cliffs: Prentice-Hall, 498p.

Lima, E.A.R. 2003. Avaliação geoquímica da ocorrência de metais pesados selecionados em sedimentos pelíticos da Plataforma Continental do Amazonas no trecho entre a foz do rio Pará e ao cabo Orange. Dissertação de Mestrado, UFPA, Belém, PA, 112p.

Meade, R.H.; Dunne, J.E..; Richey, U.; Salate, E. 1985. Storage and remobilization of suspended sediment in the lower Amazon river estuary. Nature, 278:161-163.

Moore, J.W.; Ramamoorth, S. 1984. Heavy Metals in Natural Waters. Spinger- Verlag, 268p.

Muniz, L.L.F.; Jordão, C.P.; Brume, W.; Pereira, J.L.; Reis, E.L. 1996. Retenção de zinco em solos do vale do aço mineiro, afetado pela remoção de matéria orgânica, óxido de ferro e óxido de manganês. Revista Química Nova, 19(5): 464-468.

Pereira, P.F.; Silva, J.L.; Mendes, A.S.; Siqueira, G.W. 2000. Avaliação do fósforo total e disponível em sedimentos da Plataforma Amazônica. Anais do XL CONGRESSO BRASILEIRO DE QUIMICA, Recife, PE, p.348.

Ribeiro, R. F. 1979. Um estudo sobre os metais pesados nos sedimentos da baía de Aratu (BA). Dissertação de Mestrado. Universidade Federal da Bahia, 84p.

Salomons, W.; Förstner, U. 1980. Trace metal analysis on polluted sediments. Part II: Evalution of environmental impact. Environ. Technol. Lett., p:506-517.

Salomons, W.; Förstner, U. 1984. Metals in the Hidrocycle. Berlin Springer-Verlag. 340p.

Shepard, F.P. 1954. Nomenclature based on sand-silt-clay ratios. J. Sedim. Petrol., 24(3): 151-158.

Seyler, P.T.; Boaventura, G. R. 2001. Trace elements in the mainstream Amazon river. In: McClain, M.E.; Victoria, F.R.L.; Richey, J.E. (Eds). The biogeochemistry of the Amazon basin. Oxford Press, p. 307 - 327.

Siqueira, G.W. 2003. Estudos dos teores de metais pesados e outros elementos em sedimentos superficiais do Sistema Estuarino de Santos (Baixada Santista/São Paulo) e Plataforma Continental do Amazonas (Margem Continental Norte do Brasil). Tese de Doutorado. Instituto Oceanográfico, Universidade de São Paulo, 386p.

Tavares, T.M.; Carvalho, F.M. 1992. Avaliação de exposição de populaçōes humanas a metais pesados no ambiente: exemplos do recôncavo baiano. Revista Química Nova, 15(2): 147-154.

Tessier, A.; Campbell, P.G.C.; Bisson, M. 1979. Sequential extraction procedure for the speciation of particulate trace metals. Anal. Chem., 51: 844-51.

Recebido em 21/07/2005

Aceito em 23/08/2006 